\title{
Agglomeration Detection in Circulating Fluidized Bed Boilers using Refuse Derived Fuels
}

\author{
Nathan Zimmerman ${ }^{1} \quad$ Konstantinos Kyprianidis $^{1} \quad$ Carl-Fredrik Lindberg ${ }^{1,2}$ \\ ${ }^{1}$ School of Business, Society and Engineering, Mälardalen University, Box 883, 72123 Västerås, Sweden, \\ \{nathan.zimmerman, konstantinos.kyprianidis\}@mdh. se \\ ${ }^{2}$ ABB Corporate Research, Forskargränd 8, 72178 Västerås, Sweden, carl-fredrik. lindberg@ se.abb.com
}

\begin{abstract}
The formation of agglomerates in a refuse derived fuel (RDF) fired circulating fluidized bed (CFB) boiler has been investigated by implementing a dynamic model of the combustion process. The nature of refuse derived fuel, which is complex in composition, leads to an increased tendency for agglomerate formation. Notwithstanding the fact that a robust control scheme is essential in preventing the decrease in boiler efficiency from accelerated agglomerate formation. Therefore, a mechanism for detecting agglomeration through a physical model by looking at the minimum fluidization is presented. As agglomerates form between the fuel ash and bed sand the average diameter of the sand will increase and therefore the minimum fluidization velocity. Samples of bed material have been sieved and measured from a $160 \mathrm{MW}$ circulating fluidized bed boiler fired with refuse derived fuel to determine bed material size distribution. The findings have been correlated and match an increase in the minimum fluidization velocity during a seven day sampling period where the bed material size distribution increases above the average sand diameter.
\end{abstract}

Keywords: circulating fluidized bed, agglomeration, detection, $R D F$

\section{Introduction}

The role of waste management in the 21 st century is essential in maintaining the excessive amount of waste produced each year in the world. Most developed countries have modern routines and guidelines for dealing with municipal solid waste (MSW) by sorting out recyclable, toxic, and organic materials. Some of these countries are utilizing MSW for producing refuse derived fuels (RDFs). These are used in waste incinerators for the purpose of producing heat and power. When compared to other alternatives, such as land-filling, waste incineration is more reliable and environmentally friendlier (Hernandez-Atonal et al., 2007).

Due to the complex nature of RDF, a viable option for thermal waste treatment is to use them as a source of fuel in circulating fluidized bed (CFB) boilers to produce heat and power, simultaneously solving waste and energy issues. CFB boilers are unique in design and al- low for a high degree in fuel flexibility, high combustion efficiency, lower emissions, and relatively fast response to load change (Basu and Fraser, 2015; Hernandez-Atonal et al., 2007; Gungor, 2009), and therefore can handle the complexities of RDF.

Typically, CFBs operate at a combustion temperature between $750{ }^{\circ} \mathrm{C}$ and $900{ }^{\circ} \mathrm{C}$ and use sand to fluidize the bed material. However, a large portion of the combustible material in RDF contain high levels of alkali and chlorine compounds, which both have low melting and low vaporization temperatures (Pettersson et al., 2013), and can react with the fluidizied sand to form low melting eutectics. It is crucial to maintain the operating temperature within limits. Else there is a significant risk of sand-ash reactions which can lead to agglomeration, slagging, and in the worse case scenario complete defluidization. The variability of RDF's composition, and therefore heating value, can lead to the temperature deviating above the boiler's limits for short periods, in the form of hot zones. The latter can increase the propensity of agglomerate formation either through ash melting or the ash coating of sand. Once agglomerates form they reduce the boiler's efficiency because the fluidized median is hindered and requires increasingly more air to properly combust the incoming fuel.

A dynamic model of an RDF fired CFB has been modeled after a $160 \mathrm{MW}$ industrial installation. Bed samples for a one week period have been taken and analyzed for any increase in the bed material particle diameter. The model has proven to be capable of detecting agglomerate formation off-line, showing an increase in the minimum fluidization during a period of time when there was a corresponding significant increase in particle diameter.

\section{Literature Review}

\subsection{Circulating Fluidized Bed Boilers}

The schematic illustrated in Figure 1 is that of a CFB. Its a type of boiler that uses sand as the fluidizing median, where a degree of solid reflux is achieved allowing for a more uniform temperature throughout the boiler. Major advantages include stable combustion at low temperatures $\left(750-900^{\circ} \mathrm{C}\right)$, uniform temperature distribution, large solid-gas exchange area, ability to handle problematic fuels with a large variability in size, moisture content, 


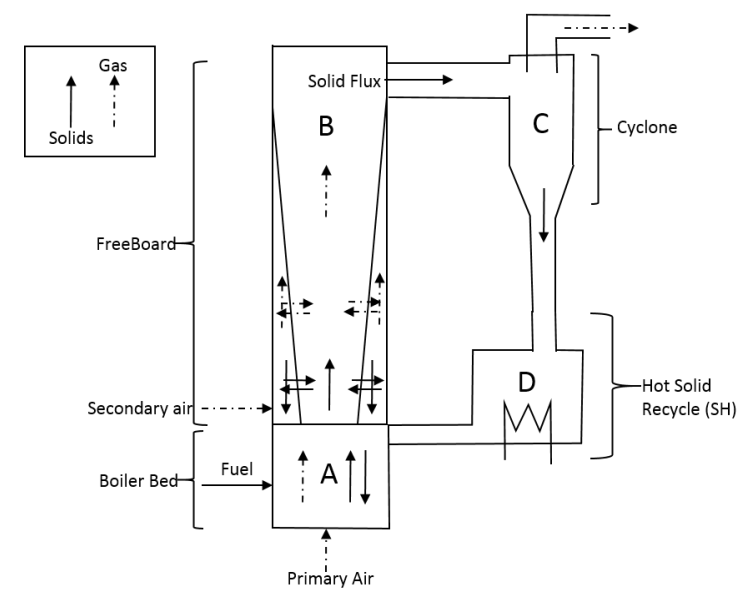

Figure 1. Circulating Fluidized Bed Boiler.

and heating value. They are capable of high heat transfer coefficients between bed and heat exchanger surfaces (Werther, 2007; Scala and Chirone, 2004).

When the fuel enters the boiler it begins to heat, where water is evaporated, volatiles begin to be released through devolatilization, ignition begins, and fragments begin to form. During this process more char becomes available for combustion. Primary air enters the bed of the boiler and entrains the sand and fuel. Above the bed is the freeboard, where secondary air is injected to allow for a higher combustion efficiency and it has been shown to reduce $\mathrm{CO}$ concentrations (Hernandez-Atonal et al., 2007). At the top of the boiler the flue gas along with a net solid flux of solids are carried to the cyclone which allows for the flue gas to be utilized in the convective section and separates fly ash from hot solids (sand and ash). The hot solids then pass through a heat exchanger to utilize their high enthalpy content, and then the cooled solids which contain unburnt char are recirculated back into the bed via the loop seal to be fully combusted.

\subsection{Characteristics of RDF}

RDF is a byproduct of home and industrial waste, but before it can be fired it needs to be sorted and treated. The waste comes into the sorting facility were it is first chopped and shredded into credit card size pieces. Metals are removed by using high power magnets and the remaining mixture passes over a large wind-sifter, which allows for heavier objects such as glass and ceramics to dropout of the mixture. The separated items are sent to recycling, where what is left can be classified as RDF, and is ready for transport into the boiler.

We can characterize what remains in the fuel as either biomass-based (climate neutral) or fossil-based, where the fossil-based constituents are typically plastics and textiles. Due to the sorting process, determining the proportions of biomass vs. fossil based portions through manual sorting is impractical. There are three established methods for determining the biomass-based portion, and therefore the fossil based portions of RDF: The Selective Dissolution
Method, The Balance Method, and the The ${ }^{14} \mathrm{C}$-Method (Staber et al., 2008). The downside is that these methods are impractical for real-time applications.

\subsection{Agglomeration}

The development of agglomerates, the binding of bed particles, is highly dependent upon the characteristics of the fuel's ash content, particle-to-particle interactions and the hydrodynamics in the boiler. As the bed material is fluidized ash can melt and bridge bed material together, as illustrated in Figure 2a. Alternatively, ash can lead to a buildup on bed material and create a sticky coating, as illustrated in Figure 2b, which causes more particles to stick together. Therefore, the likelihood of agglomeration formation is dependent upon ash characteristics and has been the topic in many studies looking at biomass and waste fuels (Elled et al., 2013; Lin et al., 2003; Scala and Chirone, 2008; Bajamundi et al., 2015; Ryabov et al., 2003). Proper fluidization is also needed to inhibit the likelihood of agglomeration. If particle mobility and mixing are below optimal it will not only cause a reduction in heat and mass transfer of the bed material (Liu et al., 2012), but the viscous materials can bond together and can lead to permanent bonds depending upon the residence time.

In a study by (Lindberg et al., 2013) they stated that the predominant ash forming elements are $\mathrm{K}, \mathrm{Na}, \mathrm{Ca}, \mathrm{Mg}, \mathrm{Fe}$, $\mathrm{Al}, \mathrm{Si}, \mathrm{P}, \mathrm{S}, \mathrm{Cl}, \mathrm{C}, \mathrm{H}$, and $\mathrm{O}$. The main ash characteristics that can lead to agglomeration come from $\mathrm{Na}$ and $\mathrm{K}$, alkali metals. When agglomerates form they disrupt the dynamics in the boiler and if the temperature exceeds the melting temperature of the particles for too long the sticky outer layer of bed material can form permanent bonds (sintering), which can lead to slagging or in worst case scenarios complete defluidization. In a study by (Chirone et al., 2006) they report that bed agglomerates begin to form near burning char because of the higher temperatures and this increases the formation of melt, or the particles stickiness. This is especially problematic because it can lead to the formation of eutectics and the escalation of adhesive forces during sintering. Eutectics formed can have melting points as low as $401{ }^{\circ} \mathrm{C}$ and $552{ }^{\circ} \mathrm{C}$ for $\mathrm{Na}_{2} \mathrm{~S}_{2} \mathrm{O}_{7}$ and $\mathrm{Na}_{3} \mathrm{~K}_{2} \mathrm{Fe}_{2}\left(\mathrm{SO}_{4}\right)_{6}$ respectively (Dunnu et al., 2010).
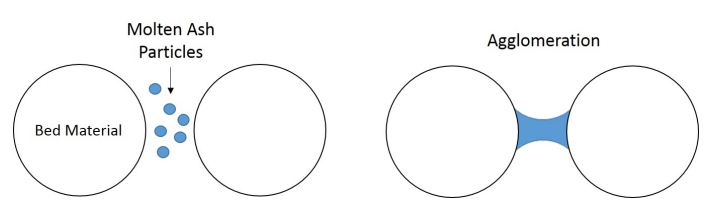

(a) Agglomeration from ash melting.

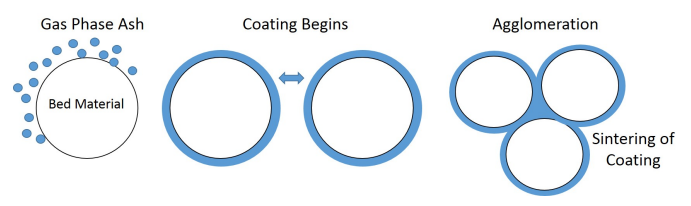

(b) Agglomeration from ash coating.

Figure 2. Prominent modes of Agglomeration. 
Agglomerates are a common occurrence in fluidized beds, but a well controlled boiler can control the fluidazation velocity or temperature well enough to break these clusters apart before sintering takes place. Presented in (Skrifvars et al., 1994; Yan et al., 2003), they discuss how the oxygen concentration in the boiler is linked to the risk of sintering, where regions of higher oxygen content can lead to hot spots. Two mechanisms, flue gas recirculation and air flow, can be used to prevent the likelihood of hot spots. Flue gas recirculation into the boiler bed will help in reducing the oxygen content as well as bed temperature. Maintaining a consistent air flow rate, depending upon the quality of the fuel, for fluidizing the bed material can also help in facilitating a well mixed combustion median in order to reduce hot spots.

A wide range of methods for agglomeration detection, when fired with biomass, have been compared and can be grouped into three categories: on-line detection, experimental methods (controlled agglomeration tests), and theoretical evaluations (fuel ash analysis), (Gatternig, 2015). The last two methods seem reasonable when considering a fuel that is relatively homogeneous, but RDF is a complex and difficult fuel to model and predict melting points, and ash composition because of its composition variability. In most industrial fluidized bed boilers it is routine to take random fuel samples to check for composition consistency. These samples could be used in agglomeration indexes (Visser, 2004; Vamvuka et al., 2008) that look at, among other elements, $\mathrm{Na}$ and $\mathrm{K}$ in the fuel to determine the likelihood of agglomerate formation. However, this approach assumes that the fuel characteristics will remain the same year after year, but in reality RDF composition is based on the consumers and such an assumption is unrealistic. Also, this method only considers a fraction of the predictability of agglomeration by looking at fuel composition and neglects fuel-ash-bed material interactions, and therefore can give a bit of insight into agglomeration tendencies and should be used cautiously. Another method for agglomeration detection is through advanced multicomponent/multiphase thermodynamic modeling (Lindberg et al., 2013), but there is currently a lack of comprehensive thermodynamic databases for ash compounds and the phases formed during combustion.

Therefore, online detection is the most suitable way to predict agglomeration when RDF is used. Current methods used for the early detection of agglomeration have been explored by looking at pressure drops and temperature fluctuations. However, at this point, the probability of defluidization is already prevalent and leaves no options for the operator but to shutdown the plant, and is not a suitable form of early detection. An alternative method, suitable for early detection, of agglomerates on a smallscale in fluidized beds has been proposed by (Nijenhuis et al., 2007). They were able to develop an early agglomeration recognition system that detects very small changes in hydrodynamic multiphase systems, and allow detection of agglomeration up to 60 minutes before occurring.
The method proposed by the authors in this paper for the detection of agglomerates is based on the minimum fluidization needed to fluidize the bed material. As the diameter of the bed material increases so will the amount of air need to fluidized the bed material in order to operate the boiler within the proper temperature limits. Hence modeling the minimum fluidization can be used in early warning detection of minimal to extreme agglomerate formation.

\section{Methodology}

The dynamic model used has been calibrated and validated using data from a RDF fired CFB, boiler 6, at MälarEnergi, in Västerås, Sweden. It was possible to back calculate the mass flow rate of fuel by conducting a heat balance on the boiler's heat exchangers. By this method it was determined that $16.8 \mathrm{~kg} / \mathrm{s}$ of RDF are fed into the boiler, taking the thermal efficiency of the boiler into consideration, this corresponds to MälarEnergi's reported value of 30 tonne/hour. The model is designed to allow for the real input of primary air, secondary air, and flue gas recirculate mass flows and corresponding temperatures. It is assumed that the mass flow rate of the fuel and its respective LHV are constant.

\subsection{Description of Model}

A model has been designed in DYMOLA using Modelica programming language. The reason for having a dynamic model is to be able to capture the transient behavior of RDF through the combustion process. With the end goal of being able to have a model that has the ability to not only monitor agglomeration, but to also be used for emissions tracking, decision support, and fault detection. The Modelica modeling language allows users to build model libraries with ability to reuse component blocks and to easily change parameters to match any complex dynamic system.

Individual component blocks were made for the CFBloop, also represented in Figure 1, for the boiler bed, freeboard, cyclone, and hot cycle recirculate (super heater (SH)) respectively. Multiple functions have been been written in order to accurately represent the thermodynamic properties for all in-coming streams, bottom and fly ash, bed material,and flue gas.

\subsection{Mass and Energy Balances}

The model is based on mass and energy balances (equations 1 and 2) used for the freeboard and bed of the boiler, cyclone, and superheater following that of a similar approach to that presented in (Basu and Fraser, 2015; Gungor, 2009). Where $i$ represents the control volume in the CFB-loop (A, B, C, D) in Figure 1, $m$ is the mass, $H$ is the enthalpy, $\alpha$ is the percentage of combustion, and $\dot{Q}$ is the heat released during combustion.

$$
\frac{d\left(m_{i}\right)}{d t}=\Sigma \dot{m}_{i n, i}-\Sigma \dot{m}_{\text {out }, i}
$$




$$
\frac{d\left(m_{i} H_{i}\right)}{d t}=\dot{m}_{i n, i} H_{\text {in }, i}-\dot{m}_{\text {out }, i} H_{\text {in }, i}+\alpha \dot{Q}_{\text {released }, i}
$$

It was possible to calculate the enthalpies of all constituent parts in the energy balance, equation 3 , where $T_{i}$ is the temperature in the control volume and $\mathrm{T}_{r e f}$ is reference temperature taken at $289.15 \mathrm{~K}$.

$$
\frac{d\left(H_{i}\right)}{d t}=C p_{i}\left(T_{i}-T_{r e f}\right)
$$

The fuel composition and flow rate is constantly changing, and in turn so is the boiler bed and flue gas temperature, so a series of functions have been developed to calculate the specific heat for each element in the control volume in the energy balance. In this way, instead of assuming constant values, the model has the capability of more accurately simulating temperature profiles for the bed and freeboard of the boiler. The function developed for calculating the specific heat $(\mathrm{Cp})$ of the gas follows the practices of (Wester, 1987), equation 4.

$$
C p=\frac{1}{T-T_{\text {ref }}} \int_{T_{\text {ref }}}^{T} \sum_{n=-1}^{n=7} a_{c}^{n}\left(\frac{T}{1000}\right)^{n}
$$

The coefficients for $a_{c}^{n}$ represent air, $\mathrm{N}_{2}, \mathrm{O}_{2}, \mathrm{CO}_{2}$, and water vapor. The gas thermophysical properties and composition were calculated by using flue gas stoichiometric calculations. The flue gas composition is found to primarily be comprised of $\mathrm{CO}_{2}, \mathrm{H}_{2} \mathrm{O}, \mathrm{O}_{2}$, and $\mathrm{N}_{2}$. Where the model uses the ultimate analysis of the fuel as input, calculates the amount of excess air in the system, and then the flue gas composition can be used to calculate the specific heat, equation 5 , as well as viscosity and density at the operating temperature.

$$
\begin{aligned}
C p_{\text {gas }}= & {\left[\mathrm{N}_{2}\right] \mathrm{Cp}_{\mathrm{N}_{2}}+\left[\mathrm{O}_{2}\right] \mathrm{Cp}_{\mathrm{O}_{2}} } \\
& +\left[\mathrm{CO}_{2}\right] \mathrm{Cp}_{\mathrm{CO}_{2}}+\left[\mathrm{H}_{2} \mathrm{O}\right] \mathrm{Cp}_{\mathrm{H}_{2} \mathrm{O}}
\end{aligned}
$$

The solids contained within each control volume consist of fuel, sand, ash, and char, as shown in equation 6 . Where $\alpha, \beta, \gamma$, and $\delta$ represent the percentage of fuel, sand, ash, and char respectively that are in the control volume $i$.

$C_{p, \text { solids }, i}=\alpha \cdot C_{p, \text { fuel }}+\beta \cdot C_{p, \text { sand }}+\gamma \cdot C_{p, a s h}+\delta \cdot C_{p, \text { char }}$

The functions for fly and bottom ash were developed by using chemical compositions found in (Chang et al., 1997). Where they analyzed the chemical composition and determined the compounds and corresponding percent composition of ash, and found that $\mathrm{CaO}, \mathrm{SiO}_{2}, \mathrm{Al}_{2} \mathrm{O}_{3}$, $\mathrm{Fe}_{2} \mathrm{O}_{3}, \mathrm{ZnO}, \mathrm{MgO}, \mathrm{Cr}_{2} \mathrm{O}_{3}$ were the major components (in decreasing order). Specific heat correlations for the compounds were developed from (Abu-Eishah et al., 2004; Karditsas and Baptiste, 1995; Madelung et al., 1999), therefore temperature dependent ash specific heat values could be estimated, equation 7 .

$$
C_{p, a s h, i}=\Sigma\left(\xi_{j} \cdot C_{p, j}\right)
$$

where $i$ represents either fly or bottom ash, $\xi$ is the compound percentage in the ash, and $j$ is the compound. With the calculation of $C p_{\text {gases }}$ and $C p_{\text {solids }}$ and corresponding mass flows equations 2 and 3 can be used to determine the boiler temperature.

\subsection{Hydrodynamics}

CFBs operate at a higher gas velocity and therefore the gas and solids within the boiler act like a fluid. In the bed of a CFB boiler there is a dense emulsion phase, where the gas moves through the inventory as large bubbles. At the top of the bed, where the secondary air input is, the bubbles burst dispersing inventory and unburnt char into the freeboard. The addition of this secondary air, theoretically, allows for a dilute well-mixed phase throughout the freeboard. The freeboard is typically further segregated into a core and annulus. The core is where the gas and solids flow upward, fine particles are carried out of the bed, and coarser particles tend to form clusters and then fall back down in the annulus region as a thin film, where the further up in the freeboard the smaller the annulus region becomes, as shown in Figure 1.

The minimum amount of air velocity required to fluidized the bed material is called the minimum fluidization velocity $u_{m f}$ and is the velocity at which the drag of the fluidized median (sand) is equal to the weight of the bed material. Following the method used in (Kunii and Levenspiel, 2013) the minimum fluidization can be determined, equation 8 .

$$
\begin{aligned}
& \frac{1.75}{\varepsilon_{m f}^{3} \phi} \cdot\left(\frac{d_{p} U_{m f} \rho_{g}}{\mu_{g}}\right)^{2}+\frac{150\left(1-\varepsilon_{m f}\right)}{\varepsilon_{m f}^{3} \phi^{2}} \cdot \frac{d_{p} U_{m f} \rho_{g}}{\mu g}= \\
& \frac{d_{p}^{3} \rho_{g}\left(\rho_{p}-\rho_{g}\right) g}{\mu_{g}^{2}}
\end{aligned}
$$

Where $\varepsilon_{m f}$ is the void fraction at minimum fluidizing conditions, $\phi$ is the sphericity of the sand, $d_{p}$ is the average diameter of sand particles, $\rho$ is either the density of the fluidizing median or sand, $\mu_{g}$ is the viscosity of the fluidizing median, and $g$ is gravity.

As the amount of air is increased into the boiler the minimum fluidazation velocity of the gas will reach the superficial velocity $\left(U_{S}\right)$ and is affected by the amount of gas, density and size in a given control area. Typically values for industrial CFBs is in the range of $5-10 \mathrm{~m} / \mathrm{s}$, (Basu and Fraser, 2015). This velocity carries bed material, ash, and unburnt char up into the freeboard, where a portion of these circulate within the boiler but there is also a net solid flux, $G_{s}$ that leaves the boiler to be recirculated back through the loop-seal. Where $G_{s}$ is equal to the amount 
of solids going up in the boiler minus the solids circulating within the boiler. A correlation between $G_{s}$ and operational conditions was presented by (Guan et al., 2010), equation 9 , where $G_{s}$ is in the rang of 200 and $400 \mathrm{~kg} / \mathrm{m}^{2}$, which is within the operating limits of the designed CFB.

$$
\frac{G_{s} d_{p}}{\mu_{g}}=547 A r^{0.248}\left(\frac{U_{s}}{\sqrt{g D}}\right)^{0.375}\left(\frac{D}{H}\right)^{0.195}
$$

Where $A r$ is Archimedes number, $D$ is the diameter of the freeboard, and $H$ is the height of the freeboard.

\section{Results and Discussion}

\subsection{Validation}

The model has been constructed to predict the performance of a $160 \mathrm{MW}$ CFB boiler. The model has been designed to predict the bed and flue gas temperatures. The validity of the model has been determined by comparing data from boiler 6 at MälarEnergi. Figure 3 illustrates a simulation, for a week, of the flue gas temperature as it exits to the cyclone. The accuracy of the model is quite good initially, less than a few percent. However, it can be seen that when there is sudden increase or decrease the model tends to underestimate, or overestimate, the respective temperature. Since the model is currently designed using a constant fuel mass flow rate and heating value it is reasonable to believe that this is attributing to the deviation in the predicted temperature. The model's profile is able to follow that of the actual profile, but if the quality of the fuel coming into the boiler is poor this would be reflected in a substantial drop in the temperature profile.

\subsection{Agglomerate Prediction}

There is a lot in the literature about methods used to predict CFB failure from agglomeration, but typically these do not take into account the impact of the combustion environment (Yan et al., 2003) like gas to particle interactions and alkali vapor condensing.

Agglomeration prediction has been studied to a lengthy extent where fossil and biomass fuels are concerned. The

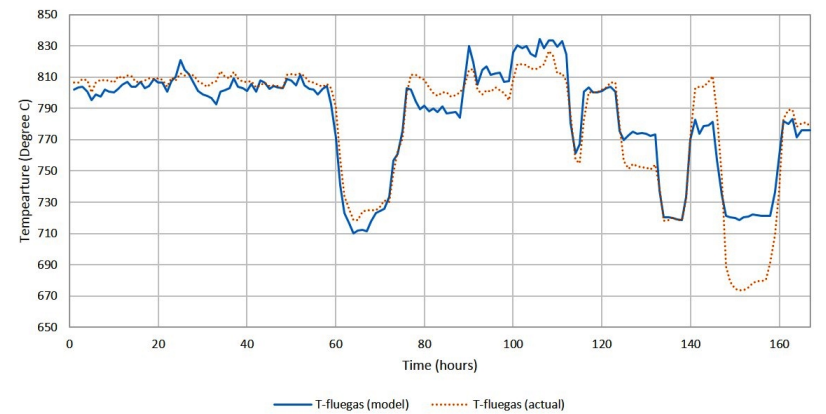

Figure 3. Temperature profile of the fluegas during the study period. standard procedure in industry for predicting agglomeration is determined from pressure drops and temperature changes (Gatternig, 2015), but it has already been mentioned that this is not suitable for early detection. For early detection, using plant process parameters, it is possible to detect agglomeration by looking at the minimum fluidization velocity, where a small increase shows that the diameter of the circulating bed material is increasing.

This is because with the onset of agglomerates and then sintering, the minimum fluidization required to fluidized the bed material will slowly increase. Therefore, agglomeration can be monitored by modeling process parameters, while operators can still keep an eye on pressure drops in the boiler bed and temperature fluctuations.

As mentioned the composition of RDF can vary from hour to hour. However, the composition of sand, with an average diameter in the range of $0.40<d_{p}<0.63$, is known and as agglomerates form this will require a higher minimum fluidization. Figure 4 confirms the presence of a relationship between the bed particle size increasing and the required increase in the minimum fluidization. Where the bed material size distribution was obtained from Mälarenergi, daily average, and the minimum fluidization is the model's prediction, taken on a daily average. This method allows for the detection of a a small change in the bed material average diameter with a suitable amount of time for the operator to make the decision to add fresh sand to the boiler before there is a subsequent formation of further agglomeration, slagging, or possibly complete defluidization.

Figure 5 illustrates the main elemental composition in $\mathrm{g} / \mathrm{kg}$ TS of the bed material samples over the week in question. Because the ash melts are coating the sand particles it is reasonable that the main composition comes from silica, with an average value of $301 \mathrm{~g} / \mathrm{kg}$ TS. However, a portion of the silica could come from glass fines in the fuel mix, but this value is unknown. It should also be noted that all of these elements, as stated before, are predominant ash forming elements. Therefore, it can be quantified that the agglomeration of the sand has occurred due to either ash melting or ash coating.

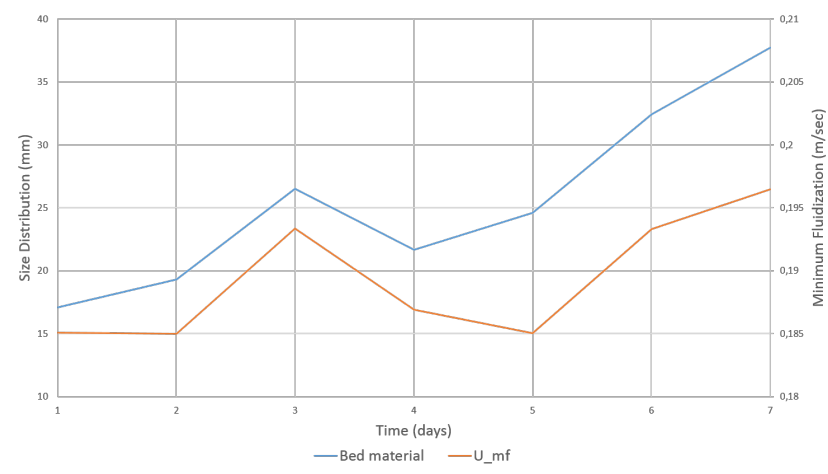

Figure 4. Bed Material Size Distribution $0.4<d_{p}<0.63 \mathrm{~mm}$ Correlates to the Minimum Fluidization. 


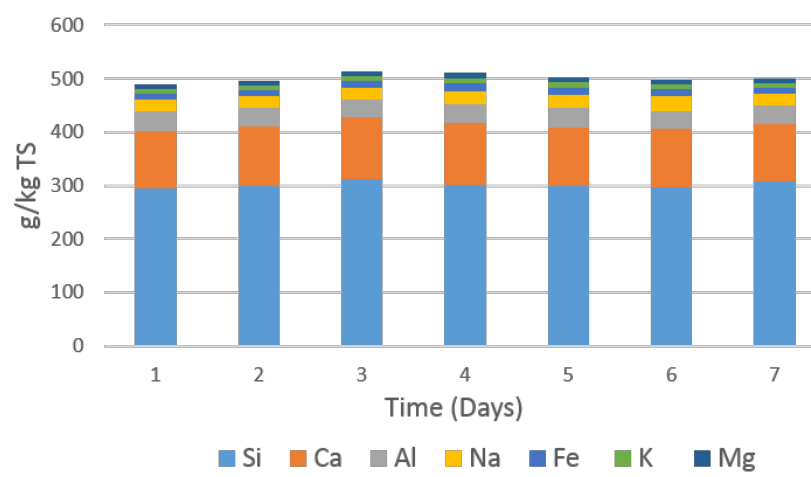

Figure 5. Primary elemental composition of the bed material during the study period.

\section{Conclusions}

The model presented shows the ability to determine the agglomeration of bed material while off-line. This has been accomplished by building a dynamic model using process parameters as input to model and calculate the minimum fluidization velocity required to maintain a boiler operating temperature within the range of $750{ }^{\circ} \mathrm{C}$ and $900{ }^{\circ} \mathrm{C}$. It should be noted that during the seven days there were periods where the fluegas temperature dropped below $750{ }^{\circ} \mathrm{C}$ and can be attributed to the possibility of poor fuel. The simulated results show that an increase in minimum fluidization velocity corresponds to an increase in bed material share that is greater than the average diameter of the sand used, $0.40<d_{p}<0.63$. Since agglomeration is prevalent no mater what the fuel source is, it is possible to implement this model as a means for real-time detection of agglomerate formation as a means for decision support to operators.

Compared to other CFB models. The library developed in this study can potentially be reused for any CFB installation through the ease of the drag-and-drop nature of object-oriented programming. The model presented has the ability to handle the transient behavior of RDF, not only for modeling agglomeration, but to also capture the dynamics of the temperature fluctuation in the boiler, hence the possibility for real-time emissions monitoring. Decision support and fault detection can also be implemented by formulating a probabilistic distribution through Bayesian nets. Only one model is needed to monitor multiple aspects of the combustion process in CFBs.

\section{Acknowledgment}

The author would like to thank Linda Svensson, Allmyr Marianne, and Lisa Granström for their assistance in data acquisition and process information on block 6 at Mälarenergi, Västerås. The authors would also like to thank Erik Dahlquist at Mälardalen University for his leadership and guidance. Funding for this work comes from The PolyPo Project within the Future Energy Re- search Profile at Mälardalen University.

\section{Nomenclature}

\section{Acronyms}

$C F B$ circulating fluidized bed

$R D F \quad$ Refuse derived fuel

\section{Greek Symbols}

$\varepsilon_{m f} \quad$ Void fraction at minimum fluidization

$\mu \quad$ Viscosity, $\frac{\mathrm{kg}}{\mathrm{ms}}$

$\phi \quad$ Sphericity

$\rho \quad$ density, $\frac{\mathrm{kg}}{\mathrm{m}^{3}}$

\section{Roman Symbols}

Ar Archimedes number, $\frac{\rho_{p}\left(\rho_{p}-\rho_{g}\right) g d_{p}^{3}}{\mu^{2}}$

Cp Specific heat, $\frac{k J}{k g K}$

$d_{p} \quad$ Particle diameter, $\mathrm{m}$

$g \quad$ Gravity, $\frac{m}{s^{2}}$

$G_{s} \quad$ Net solid flux, $\frac{\mathrm{kg}}{\mathrm{m}_{s}^{2}}$

$H \quad$ Enthalpy, $\frac{\mathrm{kJ}}{\mathrm{kg}}$

$h \quad$ Height of the freeboard, $m$

$m \quad$ mass, $\mathrm{kg}$

$Q \quad$ Heat released, KW

$T \quad$ Temperature, $\mathrm{K}$

$U_{m f} \quad$ Minimum fluidization velocity, $\frac{m}{s}$

$U_{s} \quad$ Superficial Velocity, $\frac{m}{s}$

\section{Subscripts}

g Gas

$i \quad$ Corresponding control volume

$p \quad$ Particle

ref Reference temperature, ambient

\section{References}

S. I. Abu-Eishah, Y. Haddad, A. Soliman, and A. Bajbouj. A new correlation for the specific heat of metals, metal oxides and metal fluorides as a function of temperature. Latin American Applied Research, 34(OCTOBER 2004):257-265, 2004. ISSN 03270793.

Cyril Jose E. Bajamundi, Pasi Vainikka, Merja Hedman, Jaani Silvennoinen, Teemu Heinanen, Raili Taipale, and Jukka Konttinen. Searching for a robust strategy for minimizing alkali chlorides in fluidized bed boilers during burning of high SRF-energy-share fuel. Fuel, 155(2015):25-36, 2015. ISSN 00162361. doi:10.1016/j.fuel.2015.03.087.

Prabir Basu and S A Fraser. Circulating Fluidized Bed Boilers: Design, Operation and Maintenance. Springer International Publishing, Switzerland, doi: 10.10 edition, 2015. ISBN 9783319061726. doi:10.1007/978-3319061733. 
Ni-Bin Chang, H.P. Wang, and K.S. Lin. Comparison between MSW ash and RDF ash from incineration process. Dec 1997.

Riccardo Chirone, Francesco Miccio, and Fabrizio Scala. Mechanism and prediction of bed agglomeration during fluidized bed combustion of a biomass fuel: Effect of the reactor scale. Chemical Engineering Journal, 123(3):71-80, 2006. ISSN 13858947. doi:10.1016/j.cej.2006.07.004.

Gregory Dunnu, Jörg Maier, and Günter Scheffknecht. Ash fusibility and compositional data of solid recovered fuels. Fuel, 89(7):1534-1540, 2010. doi:10.1016/j.fuel.2009.09.008.

A. L. Elled, L. E. Åmand, and B. M. Steenari. Composition of agglomerates in fluidized bed reactors for thermochemical conversion of biomass and waste fuels: Experimental data in comparison with predictions by a thermodynamic equilibrium model. Fuel, 111:696-708, 2013. ISSN 00162361. doi:10.1016/j.fuel.2013.03.018.

Bernhard Gatternig. Predicting Agglomeration in Biomass Fired Fluidized Beds. PhD thesis, 2015.

Guoqing Guan, Chihiro Fushimi, and Atsushi Tsutsumi. Prediction of flow behavior of the riser in a novel high solids flux circulating fluidized bed for steam gasification of coal or biomass. Chemical Engineering Journal, 164(1):221-229, 2010. ISSN 13858947. doi:10.1016/j.cej.2010.08.005.

Afsin Gungor. One dimensional numerical simulation of small scale CFB combustors. Energy Conversion and Management, 50(3):711-722, 2009. ISSN 01968904. doi:10.1016/j.enconman.2008.10.003.

Francisco D. Hernandez-Atonal, Changkook Ryu, Vida N. Sharifi, and Jim Swithenbank. Combustion of refusederived fuel in a fluidised bed. Chemical Engineering Science, 62(1-2):627-635, $2007 . \quad$ ISSN 00092509. doi:10.1016/j.ces.2006.09.025.

Panayiotis Karditsas and Marc-Jean Baptiste. Thermal and structural properties of fusion related materials, 1995.

Daizo Kunii and Octave Levenspiel. Fluidization engineering. Elsevier, 2013.

Weigang Lin, Kim Dam-Johansen, and Flemming Frandsen. Agglomeration in bio-fuel fired fluidized bed combustors. Chemical Engineering Journal, 96(1-3):171-185, 2003. ISSN 13858947. doi:10.1016/j.cej.2003.08.008.

Daniel Lindberg, Rainer Backman, Patrice Chartrand, and Mikko Hupa. Towards a comprehensive thermodynamic database for ash-forming elements in biomass and waste combustion: Current situation and future developments. Fuel Processing Technology, 105:129-141, 2013. doi:10.1016/j.fuproc.2011.08.008.

Zhen-Shu Liu, Tzu-Huan Peng, and Chiou-Liang Lin. Effects of bed material size distribution, operating conditions and agglomeration phenomenon on heavy metal emission in fluidized bed combustion process. Waste management (New York, N.Y.), 32(3):417-25, 2012. ISSN 1879-2456. doi:10.1016/j.wasman.2011.10.033.
O. Madelung, U. Rössler, and M. Schulz. In II-VI and IVII Compounds; Semimagnetic Compounds, volume 41B of Landolt-BÃürnstein - Group III Condensed Matter. 1999. ISBN 978-3-540-64964-9.

J. Nijenhuis, R. Korbee, J. Lensselink, J. H a Kiel, and J. R. van Ommen. A method for agglomeration detection and control in full-scale biomass fired fluidized beds. Chemical Engineering Science, 62(1-2):644-654, 2007. ISSN 00092509. doi:10.1016/j.ces.2006.09.041.

Anita Pettersson, Fredrik Niklasson, and Farzad Moradian. Reduced bed temperature in a commercial waste to energy boiler - Impact on ash and deposit formation. Fuel Processing Technology, 105:28-36, 2013. ISSN 03783820. doi:10.1016/j.fuproc.2011.09.001.

Georgy Ryabov, Dmitry Litoun, and Eduard Dik. Agglomeration of bed material: Influence on efficiency of biofuel fluidized bed boiler. Thermal Science, 7(1):5-16, 2003. ISSN 0354-9836. doi:10.2298/TSCI0301005R.

Fabrizio Scala and Riccardo Chirone. Fluidized bed combustion of alternative solid fuels. Experimental Thermal and Fluid Science, 28:691-699, 2004. ISSN 08941777. doi:10.1016/j.expthermflusci.2003.12.005.

Fabrizio Scala and Riccardo Chirone. An SEM/EDX study of bed agglomerates formed during fluidized bed combustion of three biomass fuels. Biomass and Bioenergy, 32(3):252-266, 2008. ISSN 09619534. doi:10.1016/j.biombioe.2007.09.009.

Bengt-Johan Skrifvars, Mikko Hupa, Rainer Backman, and Matti Hiltunen. Sintering mechanisms of FBC ashes. Fuel, 73(2):171-176, 1994.

Wolfgang Staber, Sabine Flamme, and Johann Feltner. Methods for determining the biomass content of waste. Waste management \& research : the journal of the International Solid Wastes and Public Cleansing Association, ISWA, 26(1):78-87, 2008. ISSN 0734-242X. doi:10.1177/0734242X07087313.

D Vamvuka, D Zografos, and G Alevizos. Control methods for mitigating biomass ash-related problems in fluidized beds. Bioresource technology, 99(9):3534-44, 2008. ISSN 09608524. doi:10.1016/j.biortech.2007.07.049.

H J M Visser. The influence of Fuel Composition on Agglomeration Behaviour in Fluidised-Bed Combustion. ECN Biomass, (September):44, 2004.

Joachim Werther. Fluidized-Bed Reactors. In Ullmann's Encyclopedia of Industrial Chemistry. 2007. ISBN 3527306730. doi:10.1002/14356007.b04_239.pub2.

L. Wester. Tabeller och diagram för energitekniska beräkningar. L. Wester, 1987.

Rong Yan, David Tee Liang, Karin Laursen, Ying Li, Leslie Tsen, and Joo Hwa Tay. Formation of bed agglomeration in a fluidized multi-waste incinerator. Fuel, 82(7):843-851, 2003. doi:10.1016/S0016-2361(02)00351-4. 